\title{
Editorial Message from the Editor-in-Chief
}

\author{
Gali Madhavi Latha ${ }^{1}$
}

Published online: 1 March 2019

(C) Indian Geotechnical Society 2019

Welcome to the first issue of Indian Geotechnical Journal in 2019. This year marks a milestone in the history of the journal because it comes with some important enhancements. The first enhancement is that the journal will consist of six issues published per year instead of four. This will enable faster processing rate of the articles and gives us scope to include more articles in a year. To get best benefits out of this improvement, we encourage more practicebased articles, state-of-the-art content and critical review articles. This will help us in scoring high in performance measures and moving up in journal ranking lists. We also changed the cover page of the journal to reflect the changes. We continue to publish excellent articles, and our rejection rates are much higher compared to many top journals in geotechnical engineering. Despite these facts, we have a fairly small number of citations, which is a big hindrance to our goal of receiving an impact factor for the journal. Lack of impact factor impedes the submission of high-performance papers to the journal because individual researchers hesitate to publish in a journal without an impact factor, due to research and grant pressures that demand quantitative performance assessment through these metrics. Though our journal has a long history and it continues to improve with time, we cannot really ignore the importance ascribed to the ranking exercises. It is time for us to look at the journal as truly international and continue to work hard to help the journal in climbing up the ranking ladder. I do not believe in rushing into shortcuts that might work in getting more citations for the articles. Instead, we should find better articles that discuss new ideas and research directions, original articles that can create deep interest in the readership of the journal and content that the researchers do not want to miss. It requires a lot of effort and commitment of the Editor to do this evaluation. Many authors may not understand the fact that the role of Editor comes with a great responsibility than power. The decisions may leave some of the authors unhappy, but this is inevitable to shape up the journal into what we are aspiring for. I thank my associate editors Prof. Deepankar Choudhury, Prof. Rajagopal and Prof. Krishna Reddy, the entire editorial board and reviewers for all their support. My warm welcome to the new members of the Editorial Board of the journal. Together we would work towards making the journal a truly influential publication. Comments, suggestions and special issue proposals are always welcome.

\footnotetext{
Gali Madhavi Latha

madhavi@iisc.ac.in

1 Bangalore, India
} 